\title{
Populational Description of Patients with Diabetes Mellitus Attended in a Family Health Center in Cuiabá, Mato Grosso
}

\section{Erick Tiago de Jesus Assunção', Ana Paula Brianezi'1, Danyelle Mariaca de Melo1, Paloma de Oliveira ${ }^{1}$, Luciana Graciela de Oliveira Boiça ${ }^{2}$, Larissa Bianca Paiva Cunha de Sá1, Alberto Krayyem Arbex ${ }^{1,3}$}

${ }^{1}$ Division of Endocrinology, IPEMED Medical School, São Paulo, Brazil

${ }^{2}$ Family and Community Health, Cuiabá, Brazil

${ }^{3}$ Diabetology Department, Malteser Krankenhaus St. Franziskus-Hospital, Flensburg, Germany

Email: dr_ericktiago@hotmail.com

How to cite this paper: Assunção, E.T.J., Brianezi, A.P., Melo, D.M., Oliveira, P., Boiça, L.G.O., Sá, L.B.P.C. and Arbex, A.K. (2017) Populational Description of Patients with Diabetes Mellitus Attended in a Family Health Center in Cuiabá, Mato Grosso. Open Journal of Endocrine and Metabolic Diseases, 7, 1-11.

http://dx.doi.org/10.4236/ojemd.2017.71001

Received: November 8, 2016

Accepted: January 2, 2017

Published: January 5, 2017

Copyright $\odot 2017$ by authors and Scientific Research Publishing Inc. This work is licensed under the Creative Commons Attribution International License (CC BY 4.0).

http://creativecommons.org/licenses/by/4.0/

\begin{abstract}
Diabetes mellitus (DM) represents one of the most serious current health problems nowadays, considering the number of people affected, its complications and morbidities. A broad analysis was performed among diabetic patients attended in the Family Health Center from the district of Baú, in Cuiabá, Mato Grosso State (Center-east Brazil), to examine the patterns of occurrence of overweight or obesity, values of glycated hemoglobin and the diagnostic of metabolic syndrome. The results show ahead a wide work that is necessary to prevent and early diagnose concerning DM, since only an intensive control will make it possible to alter the reality of the unfavorable prognosis documented.
\end{abstract}

\section{Keywords \\ Diabetes Mellitus, Obesity, Metabolic Syndrome}

\section{Introduction}

DM represents one of the most serious current health problems, if we take into consideration the number of people who are affected by it, incapacitations caused, and its early death rate, as well as the costs incurred in the control and treatment of its complications. Moreover, the world prevalence of the disease has grown to epidemic proportions. According to estimates from the International Diabetes Federation, there are currently around 387 million of diabetic patients in the planet and this number is to increase to, approximately, 471 million by 2035. Such increase in the prevalence occurs due to several environmental and 
behavioral factors such as higher longevity associated to a growing consumption of saturated fat, inactivity and, consequently, obesity [1] [2] [3] [4] [5].

It is estimated that in 2035 the number of diabetic patients in South America is going to increase in $60 \%$. Brazilian studies show a prevalence of diabetes of 13.5\% in São Carlos-SP and of 15\% in Ribeirão Preto-SP. In 2013, it was estimated that there would be $11,933,580$ people, at round the ages of 20 to 79 years old, with diabetes in Brazil [1] [3] [5].

In view of such scenario, this paper has as its main objective to accomplish a bibliographic review regarding DM, considering the most relevant aspects of such condition, focusing on the physiopathology of DM2 due to the fact that this type is the most predominant one. Together with the data found in the literature, a description of the characteristics from the diabetic population attended in the Family health center will be presented, residents from the district of Baú in the city of Cuiabá, Mato Grosso state, since such data is still in small numbers if we consider the region mentioned. Thus, the intention is to make people aware of the relevance and the necessity of the diagnosis, followed by the appropriate treatment of these patients.

\section{Diabetes Mellitus}

\subsection{Diagnosis and Classification}

The diagnostic criteria and the general classification of the diabetes proposed by the American Diabetes Association (ADA), in 2016, are gathered in Table 1 \& Table 2 [6].

Symptoms of blunt hyperglycemia include polyuria, polydipsia, weight loss, sometimes with polyphagia and blurred vision. Acutely, threatening consequences to the life of the uncontrolled diabetes are hyperglycemia with ketoacidosis and the nonketotic hyperosmolar syndrome [7].

Table 1. Criteria for the diabetes diagnosis.

Fasting glucose $\geq 126 \mathrm{mg} / \mathrm{dL}$ * ${ }^{*} \mathrm{R}$

Glucose 2 hours after overload with $75 \mathrm{~g}$ of glucose $\geq 200 \mathrm{mg} / \mathrm{dL}$ in oral test of glucose tolerance (TOTG). ${ }^{*} \mathrm{OR}$

Glycated Hemoglobin $(\mathrm{A} 1 \mathrm{c}) \geq 6.5 .{ }^{\star} \mathrm{OR}$

Random Glucose $\geq 200 \mathrm{mg} / \mathrm{dL}$ in patients with classic symptoms of hyperglycemia.

${ }^{\star}$ In the absence of proved hyperglycemia the tests should be repeated for confirmation.

Table 2. Classification of diabetes according to ADA.

1. DM type 1: destruction of $\beta$ cells, usually leading to absolute deficiency of insulin.

2. DM type 2: caused by progressive reduction of insulin secretion due to insulin resistance.

3. Gestational diabetes: diabetes diagnosed in the second or third gestational quarter that was clearly not present before.

4. Specific types of diabetes due to other causes: monogenic syndromes of diabetes (neonatal diabetes and MODY), diseases of the exocrine pancreas (such as cystic fibrosis), and drugs/chemically induced (such as the use of glucocorticoids, treatment for HIV/AIDS or after organ transplant). 


\subsection{Physiopathology}

The most relevant risk factors for the development of DM2 are: obesity, family history of diabetes, race/ethnicity (African Brazilians, Hispanics, Indigenous people Pima, etc.), age (from 45 years old), previous diagnosis of glucose intolerance, high blood pressure, dyslipidemia (HDL cholesterol $<35 \mathrm{mg} / \mathrm{dL}$ and/or triglycerides $>250 \mathrm{mg} / \mathrm{dL}$ ), history of gestational DM or fetal macrosomia and tobacco use. From these, the most important is obesity [1].

The main physiopathological mechanisms that lead to hyperglycemia in DM2 are the peripheral resistance to the action of insulin (IR) in the adipocytes and, specially, in the skeletal muscle and defective secretion of insulin by pancreas increasing the hepatic production of glucose, resulting in IR in the liver [1].

IR is a constant finding in patients with DM2 and is present years before the onset of diabetes. It manifests by the reduction in the transport and metabolism of glucose stimulated by insulin in the adipocytes and skeletal muscle and by the impairment of hepatic debit suppression from glucose, as well as being associated with the progression of diminished tolerance to glucose for DM2. It is possible that the chronic stimulation of the insulin secretion in states of IR induces the oxidative stress. In addition, the insulin has demonstrated to suppress various factors of pro-inflammatory transcription and the genes regulated by them that measure the inflammation. A deficiency in the reduction of the insulin action because of IR would result therefore in the activation of these factors of transcription and in the increase of the expression of its correspondent genes [2] [8] [9].

In the onset of the disease, the $\beta$ cells secrete enough insulin to keep the glycemic control, however, the relative or absolute deficiency of insulin surpasses causing hyperglycemia and diabetes, having, therefore, the dysfunction of $\beta$ cells as a key phenomenon in the development of diabetes [10].

Some people may have a precocious limited mass of $\beta$ cells during life because of genetic factors creating a predisposition to diabetes. However, the death of these cells may be compensated by regeneration up to a certain point. Glucose performs a central role over these factors contributing to the failure of $\beta$ cells, while transitional increases in the postprandial glycaemia may predominantly induce the proliferation of $\beta$ cells in insulin resistant patients, this adaptive mechanism may fail in the end and it may be overpassed by apoptosis from $\beta$ cells. Nevertheless, it is unlikely that glucotoxicity acts by itself, and the negative contribution of free fatty acids, lipoproteins, leptin and cytokines circulating or locally produced are going to additionally fail $\beta$ cells. These factors are going to induce necrosis or apoptosis, that in the presence of pro-inflammatory cytokines may activate specific immunologic phenomenon that will finally result in autoimmunity [11].

A close association between obesity and IR is observed in all ethnic groups, being found in all body weights, in all ages and in both genders. A series of several studies have demonstrated that the risk of diabetes and, presumably, of IR, elevates as the body fat content increases, indicating that the absolute quantity of 
body fat has an effect over the sensibility to insulin throughout a wide spectrum. On the other hand, the central fat concentration (intra-abdominal) is more likely connected to IR and a series of relevant metabolic variables, including plasmatic glucose, insulin, total plasmatic cholesterol and the concentration of triglycerides, as well as the reduction of plasmatic concentration of lipoprotein of high density (HDL) and of cholesterol, than to the total fat concentration [2].

The reason for the relation between intra-abdominal fat and the abnormal metabolism is not clearly defined, but a series of hypothesis, that are not mutually excluding, have been proposed. Firstly, the abdominal fat is richer in active lipids than the subcutaneous fat, maybe due to its higher complement of adrenergic receptors. Besides that, the fat abdominal tissue is resistant to the lipid effects of insulin, including alterations in the activity from the lipoprotein lipase that lead to an increase in the lipase activity and to a higher flow of fatty acids for the circulation, especially for the circulation access [2].

It is important to mention that the abdominal circumference (AC) is not only a clear marker of abdominal obesity, it is also largely influenced by the total obesity of the patient. Thus, the bigger the BMI, the more likely higher the AC will be. However, although AC has a great correlation with a quantity of total abdominal fat, it may not distinguish visceral fat, an important association of metabolic abnormalities, from the quantity of subcutaneous abdominal fat. Many studies have demonstrated that patients with an excess of visceral fat are characterized with the worst metabolic profile [12].

The anatomic distribution of fat seems to determine the risk of Metabolic Syndrome (MS). Obesity in the upper part of the body, contrary to obesity in the lower part of the body (the format of apple instead of pear format), is highly related to IR and to the risk of DM2. The association described between the increase of abdominal fat (upper body) and the increase of risk of coronary heart disease is related to the visceral fat (as suggested before), reason why the proportion waist-hips above 1.0 in men and higher than 0.8 in women indicates abdominal obesity. The National Cholesterol Education Program (NCEP) has suggested a waist circumference higher than $102 \mathrm{~cm}$ in men and higher than $88 \mathrm{~cm}$ in women constitute a marker for MS [2].

Obesity is associated with dyslipidemia and increase in the circulation of leptin and cytokines. The influence of dyslipidemia in the $\beta$ cells depends on the specific lipid profile of the person. Although some free fatty acids (FFAs) and lipoproteins were demonstrated as pro-apoptosis for the $\beta$ cell, others are protective. Regarding lipoproteins, while VLDL and LDL are pro-apoptosis, the HDL is protective [11].

More data has been accumulated to reinforce the concept that obesity is an inflammatory state, the plasmatic concentrations of the tumor necrosis factor alfa (TNF- $\alpha$ ), interleukin 6 (IL-6) and other inflammatory markers have been demonstrated high levels in obesity. It has also been shown that the fatty tissue expresses the majority of these markers and that the macrophages residing in the fat tissue may still be the source for pro-inflammatory factors as they modulate 
the secretion activity of the fat tissue. Recently, the mononuclear cells of a fat person, from which the monocytes are a fraction, have also shown to be in an inflammatory state, expressing high increases of pro-inflammatory cytokines and related factors. Moreover, these cells have shown significant increased connection with $\mathrm{NFk} \beta$ (nuclear factor of transcription kappa-beta), the transcription key factor in the inflammation. Also, two other important proteins, leptin and adiponectin, have to be mentioned. Although leptin is recognized in its function as a marker of satiety inhibiting ingestion of food, it also has additional roles as an immunologic marker and high concentration levels may contribute to a pro-inflammatory state of obesity and for the atherogenesis in the long term. Inversely, secreted adiponectin in abundance by the adipocyte in regular people is anti-inflammatory and potentially anti-atherogenic. In contrast to leptin, its concentration falls with the weight gain and obesity suggesting that its decrease may be a marker for atherosclerosis and coronary heart disease [9] [13].

The elevation of FFAs is prognostic for the progression of diminished tolerance to glucose for diabetes. The increase in the flow of fatty acids for the skeletal muscle related to the increase of visceral lipolysis was implicated in the inhibition of muscular capture of glucose [2]. A high plasmatic concentration of FFAs is certainly a risk factor for the development of DM2, independently of its effects on the insulin sensibility [8].

As mentioned before, the group of alterations such as the lipid profile, glucose metabolism, and in some cases, liver function and heart diseases are directly connected to overweight, and is today known as Metabolic Syndrome. Several definitions have already been proposed for the MS [1].

The proposed classification for ATP III (Evaluation and Treatment of High Blood Cholesterol in Adults)proposes the presence of 3 or more of the following criteria: 1) abdominal obesity defined by the waist $>102 \mathrm{~cm}$ in men and $>88 \mathrm{~cm}$ in women; 2) hypertriglyceridemia $\geq 150 \mathrm{mg} / \mathrm{dL}$; 3) low HDL cholesterol, $<40$ $\mathrm{mg} / \mathrm{dL}$ in men and $<50 \mathrm{mg} / \mathrm{dL}$ in women; 4) high blood pressure $\geq 130 / 85$ $\mathrm{mmHg}$; 5) fasting glycaemia $\geq 110 \mathrm{mg} / \mathrm{dL}$. Created in 2001, it was the most used for a long time in the daily clinical practice; however, some points need to be discussed. Only patients with glycemic intolerance and/or DM are included in this classification, discarding the IR criterion and the absence of an IR marker (for instance: fasting insulin, HOMA), which excludes an important group of patients [1] [12] [13].

Three scenarios have been proposed to explain the relation between visceral fat and MS. 1) the hyper lipolysis state of omental tissue, that shows IR, contributes for the exposition (through portal circulation) of the liver to high concentrations of FFAs, damaging various hepatic metabolic processes conducting to hyperinsulinemia, intolerance to glucose (increase in the hepatic production of glucose), and hyper triglyceridemia (increase in VLDL and secretion of lipoprotein B); 2) the fat tissue is a great endocrinal organ that is the source of adipokines such as adiponectin and inflammatory cytokines that contribute to IR and to a pro-inflammatory state, thrombosis and hypertensive of visceral obesity 
(what has been previously commented with more details); (3) excess of visceral fat is only (or partially) a marker of relative incapacity of the subcutaneous adipose tissue to continue acting as a metabolic deposit for its inability to expand (lipodystrophy) or because it has become hypertrophied, dysfunctional and resistant to insulin. Nevertheless, a more plausible explanation for the metabolic abnormalities of the abdominal obesity is that all those mechanisms are involved [12].

MS has a growing prevalence all over the world, which is largely connected to the increase of obesity and an inactive life style making it a problem of Public Health as much as ambulatory problem. In the area of Public Health, more attention must be given to the modifications in the life style from the population in general aiming at reducing obesity and increasing the practice of exercises. In hospital and ambulatory levels, patients with MS must be individually identified as well as their multiple risk factors, including those that remit in that life style and may be reduced [14].

\section{Treatment Target}

The first target in the clinic practice of MS is to reduce the risk for atherosclerotic disease, with a top-notch therapy that relates to the main risk factors: LDL above the target, hypertension and diabetes. Prevention of DM2 is another important target when it is not present. For those with established diabetes, the handling of risk factors must be intensified. The main emphasis on handling MS itself is to mitigate the modifying underlying risk factors (obesity, inactiveness and atherogenic diet) through effective changes in the life style that will reduce all metabolic risks [13].

DM2 may be prevented or, at least, delayed by means of interventions in the holders of pre-diabetes. These patients must alter their life style, with changing of eating habits, weigh loss (reduction of at least $5 \%$ to $10 \%$ of body weight) in case of patients who are overweight or obese, as well as the increase of exercises, for example walks for at least 150 minutes per week [15]. This way, the programs of primary care of DM2, based on intervention on diet and exercises, aim at combating the excess of weigh for people who are more prone to developing diabetes, particularly in those with intolerance to diminished glucose. The results from Diabetes Prevention Program (DPP) have shown a reduction of $58 \%$ in the incidence of cases of DM with the stimulus of a healthy diet and practice of exercises, this intervention has proven to be more effective than the use of metformin [10].

Some important measures in the secondary prevention of DM2 are: 1) treatment of high blood pressure and dyslipidemia, that substantially reduces the risk of complications from DM; 2) prevention of feet ulcers and amputation of inferior members by means of specific care; 3 ) diagnosis and early treatment of retinopathy; 4) testing for microalbuminuria is a recommended procedure to prevent or delay the progression of renal insufficiency; 5) measures to reduce cigarette consumption assist in controlling DM, as smoking is associated to a poor 
control of diabetes and causally hypertension [10].

The intensive control of glucose must always be sought (recommendations are show on Table 3), as it is such fact that diminishes the risk of microvascular complications. Intensive therapy of DM patients also demonstrates an improvement in their quality of life, as it may be expected a gain of the their life expectancy [16] [17].

The ongoing increase in the incidence of the diabetes diagnosis combined with the decreasing death rate has been leading to an accelerated increase in the risk of complications related to the increase in the age with the disease. Such findings demonstrate that it is necessary a continuous advance in the health care and costs, each time more elevated, to control the disease, and it emphasizes the effective necessity for intervention in order to reduce its incidence [18].

\section{Results}

Data collection was performed with 30 diabetic patients attended in the Family Health center in the district of Baú, in the city of Cuiabá, Mato Grosso state, during the months of October to December 2015 through medical appointments and review of medical charts. The total population of the unit is of 3065 enrolled patients, with 89 diabetic patients. The majority of these patients have health care and/or are enrolled in health insurances, having a follow-up and treatment in private clinics, this way, not all patients have follow-ups regularly in the unit and therefore have not participated of the study.

If we observe the total population of the Unit, 89 of them received the diabetes diagnosis and are under follow-up/treatment. This number represents only $3 \%$ of the total population, which is considered to be low if we take the values of $13.5 \%$ to $15 \%$ found in the studies of this bibliographic review and the growing prevalence of the disease worldwide. The age of the patients varied from 38 to 80 years of age. From those, 21 are within the age above 60 years old, and hence are considered elderly ( $70 \%$ of the total), which reflects the high prevalence of DM in this population range. From the patients that took part of the studies, 16 of them were male and 14 were female, showing also the equal prevalence of the disease practically in both genders.

As for BMI, the following results on Graphic 1 were found in the patientsnormal: 4, overweight: 13 , obese $1: 7$, obese $2: 3$, obese $3: 3$. Practically all patients are in the range of BMI that corresponds to overweight or obesity, what only reinforces the presence of obesity as the main risk factor in the development of diabetes.

Table 3. Recommendations of Glucose for Adults with Diabetes, ADA 2016.

A1C: $<7 \%$

Pre-prandial Capillary Plasmatic glucose: 80 - $130 \mathrm{mg} / \mathrm{dL}$

Peak of Pre-prandial Capillary Plasmatic glucose: $<180 \mathrm{mg} / \mathrm{dL}$

${ }^{\star}$ Glycemic target more or less rigid may be appropriate for specific patients. 


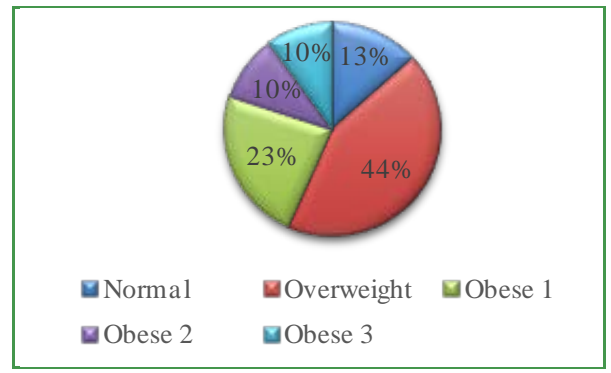

Graphic 1. BMI Interpretation.

According to the values of the waist measures found, as shown on Graphic 2, 20 patients were with altered values, reflecting the presence of overweight or obesity as a risk factor for MS and DM. According to the gender, the AC was altered in 8 male patients and in 12 female patients, what is practically its totality (86\%).

Although its efficacy in the glycemic control, only 6 patients (20\%) make regular use of insulin as a means of treatment. From the fasting glycaemia values found, only 9 patients (30\%) present values $<100 \mathrm{mg} / \mathrm{dL}$ and 17 patients (57\%) present values $\geq 130 \mathrm{mg} / \mathrm{dL}$. The maximum and minimum values of fasting glycaemia were of 74 and $329 \mathrm{mg} / \mathrm{dL}$ respectively.

The values for glycated hemoglobin presented on Graphic 3 varied from 5.1 to $14.4 \%$. According the overall target of treatment, 13 patients presented values $\geq 7 \%$ representing $43 \%$ of the total. This is an elevated value if we consider the necessity of intensive glycemic control.

The minimum value of total cholesterol was of $99 \mathrm{mg} / \mathrm{dL}$ and the maximum of $290 \mathrm{mg} / \mathrm{dL}$ in the studied patients. In relation to HDL, in male patients 6 presented smaller values than $40 \mathrm{mg} / \mathrm{dL}(37 \%)$ and in the female patients only 5 (36\%) presented values $<50 \mathrm{mg} / \mathrm{dL}$ (although there were in this group more patients with altered values of $\mathrm{AC}$ ). The values for triglycerides found varied from 56 to $498 \mathrm{mg} / \mathrm{dL}$. From these, 15 patients presented values $\geq 150 \mathrm{mg} / \mathrm{dL}$, representing $50 \%$ as shown on Graphic 4 . As for the LDL values, 11 patients presented values $\geq 100 \mathrm{mg} / \mathrm{dL}$, in a total of $37 \%$ presented on Graphic 5 .

According to the criteria on MS proposed by ATP III, 14 patients of the study may be diagnosed with the syndrome, which represent $47 \%$ of the studied patients shown on Graphic 6.

\section{Conclusions}

Diabetes mellitus is without a doubt a great public health problem presenting an ascending curve of prevalence worldwide, having a great extent, impact and severity for the patients and the society. This happens due to several factors that reflect the current life style of the population that has become each day more inactive, adherent to inappropriate diets, composed in its majority of fast meals with highly industrialized products full of fats and carbohydrates, associated to the lack of exercises.

Not only for reason of its prevalence but DM2 is also a silent disease. In most 


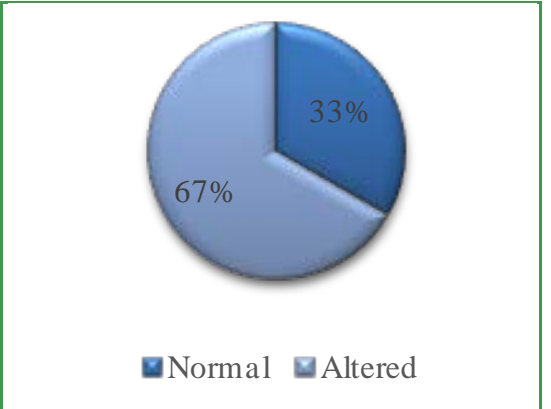

Graphic 2. Abdominal Circunference.

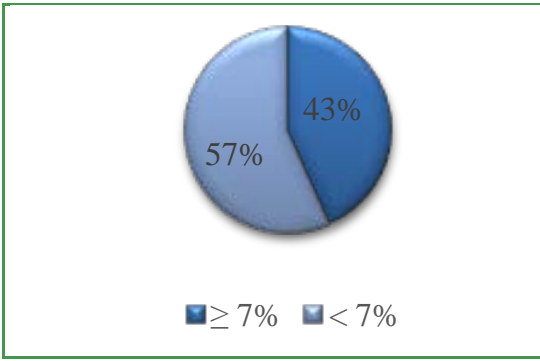

Graphic 3. Glycated Hemoglobin.

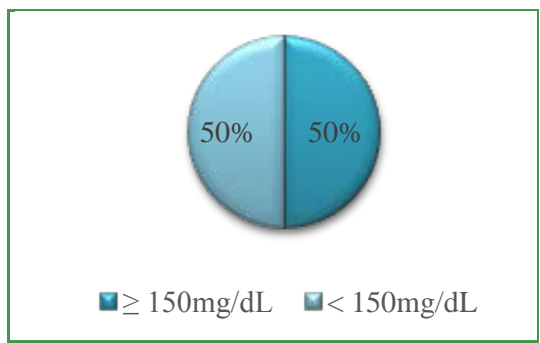

Graphic 4. Triglycerides.

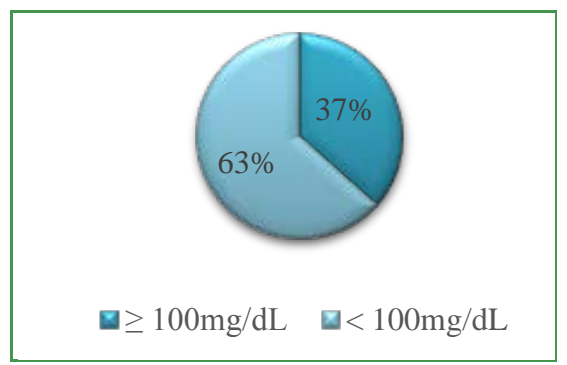

Graphic 5. LDL.

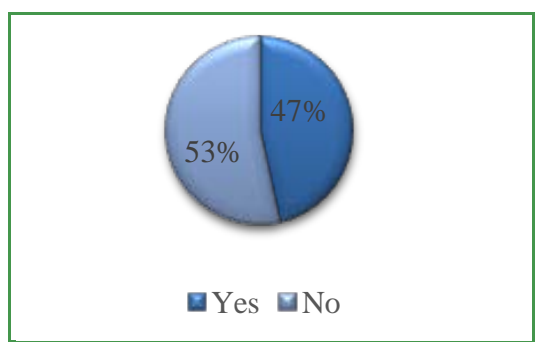

Graphic 6. Metabolic Syndrome (ATP III). 
cases, it only manifests itself usually after several years of its installation and already associated to chronical complications. In addition, in its majority it is irreversible causing direct harm to the quality of life of the patients, composed by an age rate each day younger, bringing yet a major impact to the economically active population. Such fact is worrying as the elders have been increasing and they are going to depend every day more on financial resources.

The role of the doctors is of great importance in this scenario, they must be always attentive to the several risk factors. Data of great relevance such as BMI and AC may be easily obtained while in the appointment with a patient (in this study, only $13 \%$ of the patients were thin, and almost $70 \%$ presented altered values of $\mathrm{AC}$ ); and if such data are altered doctors have to pay attention to the presence of insulin resistance and metabolic syndrome. They should also guide the patients towards new conducts, preventive actions and diagnosis as well as control of their condition. It is also very important to pay attention to the targets for treatment, informing the patients and family members about the consequences of a wrong handling of the disease (values of HbAlc higher than the standardized target represented by $43 \%$ of the patients from this study).

In face of all the evidence found, it is necessary to offer a bigger incentive to prevention, making an early diagnosis of DM. It is so because it is only by means of an intensive and proper control, aiming at the treatment targets, composed by changes in the habits of life focusing on diet and exercise, multidisciplinary follow-up and regular appointments to control overweight and obesity, metabolic syndrome and all its consequences, besides the correct use of insulin and other necessary medications, that the reality of unfavorable prognosis of this condition can be changed.

\section{References}

[1] Vilar, L. (2013) Endocrinologia clínica. 5th Edition, Guanabara Koogan, Rio de Janeiro.

[2] Kronenberg, H.M., et al. (2010) Williams Tratado de endocrinologia. 11th Edition, Elsevier, Rio de Janeiro.

[3] IDF Diabetes Atlas (2014) International Diabetes Federation. http://www.idf.org/diabetesatlas/update-2014

[4] Geiss, L.S., Wang, J., Cheng, Y.J., Thompson, T.J., Barker, L., Li, Y., Albright, A.L. and Gregg, E.W. (2014) Prevalence and Incidence Trends for Diagnosed Diabetes among Adults Aged 20 to 79 Years, United States, 1980-2012. Journal of the American Medical Association, 312, 1218-1226.

http://jama.jamanetwork.com/article.aspx?articleID=1906616 https://doi.org/10.1001/jama.2014.11494

[5] (2015) Diretrizes da Sociedade Brasileira de Diabetes: 2014-2015/Sociedade Brasileira de Diabetes; [organização Jose Egídio Paulo de Oliveira, Sergio Vêncio]. AC Farmacêutica, São Paulo. http://www.diabetes.org.br/images/2015/area-restrita/diretrizes-sbd-2015.pdf

[6] American Diabetes Association (2016) Standards of Medical Care in Diabetes. Diabetes Care.

http://care.diabetesjournals.org/content/suppl/2015/12/21/39.Supplement 1.DC2/2 016-Standards-of-Care.pdf 
[7] American Diabetes Association (2010) Diagnosis and Classification of Diabetes Mellitus. Diabetes Care, 33, S62-S69.

http://care.diabetesjournals.org/content/33/Supplement_1/S62.full.pdf+html

[8] Cnop, M., Welsh, N., Jonas, J.-C., Jörns, A., Lenzen, S. and Decio L. Eizirik (2005) Mechanisms of Pancreatic $\beta$-Cell Death in Type 1 and Type 2 Diabetes. Diabetes, 54, S97-S107. http://diabetes.diabetesjournals.org/content/54/suppl 2/S97.full.pdf+html

[9] Dandona, P., Aljada, A., Chaudhuri, A., Mohanty, P. and Garg, R. (2005) Metabolic Syndrome-A Comprehensive Perspective Based on Interactions between Obesity, Diabetes, and Inflammation. Circulation, 111, 1448-1454. http://circ.ahajournals.org/content/111/11/1448.full.pdf+html

[10] Savage, D.B., Petersen, K.F. and Shulman, G.I. (2007) Disordered Lipid Metabolism and the Pathogenesis of Insulin Resistance. Physiological Reviews, 87, 507-520. http://physrev.physiology.org/content/physrev/87/2/507.full.pdf

[11] Donath, M.Y., Ehses, J.A., Maedler, K., Schumann, D.M., Ellingsgaard, H., Eppler, E. and Reinecke, M. (2005) Mechanisms of $\beta$-Cell Death in Type 2 Diabetes. Diabetes, 54, S108-S113. http://diabetes.diabetesjournals.org/content/54/suppl 2/S108.full.pdf+html

[12] Despreés, J.-P., Lemieux, I., Bergeron, J., Pibarot, P., Mathieu, P., Larose, E., et al. (2008) Abdominal Obesity and the Metabolic Syndrome: Contribution to Global Cardiometabolic Risk. Arteriosclerosis, Thrombosis, and Vascular Biology, 28, 1039-1049. http://atvb.ahajournals.org/content/28/6/1039.full.pdf+html

[13] Grundy, S.M., Cleeman, J.I., Daniels, S.R., Donato, K.A., Eckel, R.H., Franklin, B.A., et al. (2005) Diagnosis and Management of the Metabolic Syndrome-An American Heart Association/National Heart, Lung, and Blood Institute Scientific Statement. Circulation, 112, 2735-2752. http://circ.ahajournals.org/content/112/17/2735.full.pdf+html

[14] Alberti, K.G., Eckel, R.H., Grundy, S.M., Zimmet, P.Z., Cleeman, J.I., Donato, K.A., et al. (2009) Harmonizing the Metabolic Syndrome-A Joint Interim Statement of the International Diabetes Federation Task Force on Epidemiology and Prevention. Circulation, 120, 1640-1645.

[15] Conduta Terapêutica no Diabetes Tipo 2: Algoritmo SBD 2014/Sociedade Brasileira de Diabetes.

http://www.diabetes.org.br/diretrizes-e-posicionamentos

[16] (1998) Intensive Blood-Glucose Control with Sulphonylureas or Insulin Compared with Conventional Treatment and Risk of Complications in Patients with Type 2 Diabetes (UKPDS 33). The Lancet, 352, 837-853.

http://www.ncbi.nlm.nih.gov/pubmed/9742976

[17] (1996) Lifetime Benefits and Costs of Intensive Therapy as Practiced in the Diabetes Control and Complications Trial. JAMA, 276, 1409-1415.

http://www.ncbi.nlm.nih.gov/pubmed/8892716 https://doi.org/10.1001/jama.1996.03540170053032

[18] Gregg, E.W., Zhuo, X., Cheng, Y.J., Albright, A.L., Narayan, K.M. and Thompson, T.J. (2014) Trends in Lifetime Risk and Years of Life Lost Due to Diabetes in the USA, 1985-2011: A Modelling Study. The Lancet Diabetes \& Endocrinology, 2, $867-$ 874. http://www.thelancet.com/pdfs/journals/landia/PIIS2213-8587(14)70161-5.pdf 
Submit or recommend next manuscript to SCIRP and we will provide best service for you:

Accepting pre-submission inquiries through Email, Facebook, LinkedIn, Twitter, etc. A wide selection of journals (inclusive of 9 subjects, more than 200 journals)

Providing 24-hour high-quality service

User-friendly online submission system

Fair and swift peer-review system

Efficient typesetting and proofreading procedure

Display of the result of downloads and visits, as well as the number of cited articles Maximum dissemination of your research work

Submit your manuscript at: http://papersubmission.scirp.org/

Or contact ojemd@scirp.org 